\title{
EVALUATION OF ANTICANDIDAL EFFECTS OF ESSENTIAL OILS OF COMMERCIAL LAVENDER (Lavandula angustifolia Miller) IN COMBINATION WITH KETOCONAZOLE AGAINTS SOME Candida Berkhout STRAINS
}

\author{
Gamze GÖGER ${ }^{1 *}$, Burcu AKÇAL ÇOMOĞLU², Gökalp İŞCAN ${ }^{3}$, Fatih DEMİRCİ ${ }^{4}$ \\ ${ }^{1}$ Trakya University, Faculty of Pharmacy, Department of Pharmacognosy, Edirne, TURKEY \\ ${ }^{2}$ Eskişehir Osmangazi University, Graduate School of Natural and Applied Sciences, Eskişehir, TURKEY \\ ${ }^{3}$ Anadolu University, Yunus Emre Vocational School, Eskişehir, TURKEY \\ ${ }^{4}$ Anadolu University, Faculty of Pharmacy, Department of Pharmacognosy, Eskişehir, TURKEY
}

Cite this article as:

Göger G., Akçal Çomoğlu B., Işcan G., Demirci F. 2020. Evaluation of Anticandidal Effects of Essential Oils of Commercial Lavender (Lavandula angustifolia Miller) in Combination with Ketoconazole Againts some Candida Strains. Trakya Univ J Nat Sci, 21(1): 13-19, DOI: $10.23902 /$ trkjnat.590839

Received: 11 July 2019, Accepted: 27 November 2019, Online First: 3 December 2019, Published: 15 April 2020

Edited by:

Mustafa Yamaç

*Corresponding Author:

Gamze Göger

gamzegoger@trakya.edu.tr

\section{ORCID ID:}

orcid.org/0000-0003-2978-5385

Key words:

Lavender (Lavandula angustifolia)

Ketoconazole

Candida albicans

Candida glabrata

Candida krusei

\begin{abstract}
Application of combination studies with essential oils and standard antifungal drugs may reduce adverse effects of synthetic drugs and serve as alternative approach against various pathologies including candidiasis. The aim of the present study was to determine the interaction of two commercial lavender (Lavandula angustifolia Miller) essential oils in combination with ketoconazole against clinical and standard strains of the human pathogens Candida albicans ATCC 10231, C. krusei NRRL Y-7179 and C. glabrata ATCC 66032. The chemical compositions of the investigated essential oils were confirmed both by gas chromatography/flame ionization detector (GC/FID) and gas chromatography/mass spectrometry (GC/MS) methods. Anticandidal activities of the essential oils were screened in vitro by the microdilution method. The resulting interaction of combining lavender essential oils and ketoconazole was tested using the checkerboard method. The results showed that the interaction between essential oils and ketoconazole revealed additive and indifferent effects against the tested strains. In conclusion, the effects observed by the combination of lavender essential oils and ketoconazole may be encouraging to be used against pathogenic Candida strains.
\end{abstract}

Özet: Uçucu yağların standart antifungal maddeler ile kombinasyonları, sentetik ilaçların olumsuz etkilerini azaltabilir ve kandidiyaz dahil olmak üzere çeşitli patolojilere karşı alternatif bir yaklaşım olarak kullanılabilir. Bu çalışmanın amacı, Farmakope kalitesindeki Lavanta (Lavandula angustifolia Miller) uçucu yağlarının ketokonazol ile kombinasyonlarının patojen Candida albicans ATCC 10231, C. krusei NRRL Y-7179 ve C. glabrata ATCC 66032 suşlarına karş1 antikandidal etkinliğini belirlemektir. İncelenen uçucu yağların kimyasal içerikleri hem gaz kromatografisi/alev iyonlaşma dedektörü (GK / AİD) hem de gaz kromatografisi/kütle spektrometresi (GK/KS) yöntemleriyle belirlenmiştir. Esansiyel yağların antikandidal aktiviteleri, mikrodilüsyon metodu ile in vitro olarak incelenmiştir. Lavanta uçucu yağları ve ketokonazol kombinasyon çalışmaları dama tahtası yöntemi kullanılarak test edilmiştir. Lavanta uçucu yağları ile ketokonazol kombinasyon çalışması sonuçları, test edilen tüm Candida suşlarına karşı "aditif" ve "indiferent" etkili olduğu görülmüştür. Sonuç olarak, lavanta uçucu yağlarının ketokonazol kombinasyonu ile gözlemlenen etkiler, patojenik Candida suşlarına karşı kullanımda etkili olabilir.

\section{Introduction}

Infectious diseases have recently increased the prolonged use of various antifungal drugs, contributing to the development of drug resistance against some species of the fungal genus Candida Berkhout, such as the azoleresistant Candida albicans (Robin) Berkhout strains along with $C$. krusei. In addition, many cases have been attributed to Candida infections particularly in persons with hematologic malignencies and transplant recipients patients (Pfaller et al. 2008).
The antifungal effect of azoles is due to their actions in inhibition of ergosterol biosynthesis on fungal cell membranes (Casalinuovo et al. 2004, Sardi et al. 2013). Currently used antifungal drugs may have the risk of toxicity, may result drug-drug interactions and lack of fungicidal efficacy. Furthermore, resistance to these drugs often develops rapidly (Metzger \& Hofmann, 1997, Pinto et al. 2009). 
Plants are known to produce a great variety of compounds. Particularly, aromatic plants have been used in folk medicine as antimicrobial agents since ancient times. (Hosseinzadeh et al. 2015). Essential oils (EOs) of many plants are known to possess a large number of pharmacologically active compounds and have antimicrobial activity. EOs show a wide-spectrum antimicrobial activity, including disruption of cellmembrane structures, leading to an alteration in membrane permeability and a consequent leakage of cell contents (Cox et al. 2000, Chen et al. 2013). For instance, recent studies on antifungal activities of some EOs have shown disruption of the fungal membrane (Pinto et al. 2006, Khan et al. 2010, Samber et al. 2015).

With this in mind, combination of antifungal therapies with natural sources may be achieved to overcome the resistance against Candida species. Specifically, EOs are known to be used in therapeutic preparations for centuries (Hosseinzadeh et al. 2015). The EOs of various Lavandula species from Lamiaceae are well known to have antimicrobial activities along with other effects they posses (Cavanagh \& Wilkinson 2002, Fismer \& Pilkington 2012). Thus, using the combinations of EOs with standard antifungal drugs employ as an alternative approach against various pathologies including candidiasis and may reduce adverse side effects, lower the dose and decrease toxicity (Cottarel \& Wierzbowski 2007). EOs of various plants have been previously investigated for their antifungal efficacy in combination with some antifungal drugs and proved to be successful (Shin \& Kang 2003, Shin 2003, Amber et al. 2010, Göger et al. 2018). Shin \& Kang (2003) reported that EO fraction of Agastache rugosa combined with ketoconazole was found to be synergistic against the opportunistic fungus Blastoschizomyces capitatus. Pelargonium graveolens EO fractions were demonstrated to have additive effects with amphotericin B and ketoconazole against Aspergillus species (Shin 2003). In more recent studies, Ocimum sanctum EO and its combination with two azoles, fluconazole and ketoconazole, were studied against resistant isolates (Amber et al. 2010). Matricaria recutita EO was combined with fluconazole against $C$. albicans (Göger et al. 2018). It thus appears that, although proved to have antimicrobial activities when tested alone, studies on combination of lavender EOs with antifungal drug are rather limited. In one recent study, nystatin was tested in combination with Lavandula angustifolia EO against $C$. albicans ATCC 10231 and an indifference effect was observed for the combination (De Rapper et al. 2016)

This study was performed with the aim of identification of chemical compositions of two EOs of lavender (L. angustifolia Miller) by GC/FID and GC/MS analytical methods and evaluate their anticandidal activities with ketoconazole by microdilution and checkerboard methods against C. albicans ATCC 10231, C. krusei NRRL Y-7179 and C. glabrata ATCC 66032 strains.

\section{Materials and Methods}

\section{Materials}

Two commercial Lavender EOs were purchased from Sevil (Turkey) and Caesar \& Lorethz GmbH (Hilden, Germany) companies and were labeled as L1 and L2, respectively. The standard powders of ketoconazole and resazurin were obtained from Sigma-Aldrich.

Anticandidal activities of the EOs of L1 and L2 were tested against standard (C. albicans ATCC 10231, C. krusei NRRL Y-7179 and C. glabrata ATCC 66032) and clinical (C. albicans, C. krusei and C. glabrata) isolates provided from Akdeniz University, Faculty of Medicine, Antalya.

\section{$\underline{G C / F I D \text { and GC/MS Analyses }}$}

\section{GC /FID analysis}

The EOs were analyzed by capillary GC using the Shimadzu GC 2010 system. The column and analysis conditions used for GC/MS were also applied for GC. FID detector temperature was $250^{\circ} \mathrm{C}$. In order to get the same elution order with GC/MS, injections were done by using the same column and operational parameters.

\section{GC/MS analysis}

The GC/MS analysis was realized with the Shimadzu GC 2010 system. CP-Sil 5 CB column ( $25 \mathrm{~m}$ x $0.25 \mathrm{~mm}$ $\varnothing, 0.25 \mu \mathrm{m}$ film thickness) was used with helium as the carrier gas ( $1 \mathrm{~mL} / \mathrm{min})$. GC oven temperature was kept at $60^{\circ} \mathrm{C}$ for $10 \mathrm{~min}$ and programmed to $260^{\circ} \mathrm{C}$ at a rate of $4^{\circ} \mathrm{C} / \mathrm{min}$, and kept constant at $260^{\circ} \mathrm{C}$ for $5 \mathrm{~min}$. Split ratio was adjusted to 50:1. The injector temperature was at $250^{\circ} \mathrm{C}$. MS were recorded at $70 \mathrm{eV}$, where the mass range was from $m / z 35$ to 450 .

\section{Identification of the volatile components}

Mass spectrometry (MS) was used to characterize the volatiles by comparing their relative retention times with those of authentic samples or by comparison of their relative retention index (RRI) to series of $n$-alkanes. Computer matching against commercial (Wiley GC/MS Library, MassFinder 3 Library) (McLafferty \& Stauffer 1989, Koenig et al. 2004) and in-house "Başer Library of Essential Oil Constituents" built up by genuine compounds and components of known oils, as well as MS literature data (Joulain \& Koenig 1998, ESO (1998)) were also used for the identification.

\section{Determination of minimum inhibitory concentration (MIC)}

Anticandidal activities were performed according to the adapted guidelines of Clinical and Laboratory Standards Institute (CLSI) M27-A2 standard method. Minimum inhibitory concentrations (MIC) of EOs of L1 and L2 and ketoconazole were determined using the standard and clinically isolated Candida isolates (see above).

Stock solutions of EOs and ketoconazole were dissolved in DMSO. EOs were diluted two-fold initially, with a final concentration range $2560-5 \mu \mathrm{g} / \mathrm{mL}$, whereas the ketoconazole was diluted from 64 to $0.125 \mu \mathrm{g} / \mathrm{mL}$. 
Candida cultures with a final inoculum size of $1 \times 10^{3}$ colonies forming units (CFU/mL) were prepared. A $10 \mu \mathrm{L}$ of the suspensions at $10^{3} \mathrm{CFU} / \mathrm{mL}$ were inoculated into a two-fold diluted solutions of the tested EOs and ketoconazole in 96 well microplates. The microplates were incubated at $35^{\circ} \mathrm{C}$ for $48 \mathrm{~h}$. Microbial growth was visualized by adding $20 \mu \mathrm{L}$ resazurin $(0.01 \%)$. MIC was defined as the lowest concentration, which did not result in any visible growth compared with the control plates. Microplates free of antifungal standards were used as the growth controls. Negative controls were used to confirm sterility and the effects of the solvents. Assays were undertaken in triplicate.

Combination of Lavender EOs and ketoconazole by the checkerboard method

The antifungal interaction between ketoconazole and EOs of L1 and L2 were studied by the checkerboard method using a 96-well plate using an 8-by-8 well configuration (Van Vuuren et al. 2009). EOs of L1 and L2 and ketoconazole were prepared as serial dilutions using the same solvents (medium) in the MIC test.

$50 \mu \mathrm{L}$ aliquots of each EOs were added to the wells of a 96-well plate in a vertical orientation and $50 \mu \mathrm{L}$ aliquots of each ketoconazole dilution were added in a horizontal orientation so that the plate contained various concentration combinations of the EOs and ketoconazole. Growth controls were applied in wells free of antifungal standards. Negative control was also applied to confirm sterility. Each well was inoculated with $100 \mu \mathrm{L}\left(5 \times 10^{3}\right.$ CFU per well) of one of the six Candida suspensions and incubated at $35^{\circ} \mathrm{C}$ for 48 hours. Following the incubation, $20 \mu \mathrm{L}$ resazurin was added to the wells and the wells were left at $35^{\circ} \mathrm{C}$ for $2 \mathrm{~h}$. Growth in wells was indicated by the color change from blue to pink.

In vitro interaction between Lavender EOs and ketoconazole were determined by using the fractional inhibitory concentrations (FIC). The FIC is expressed as the interaction of two compounds, where the concentration of each test compound in combination is expressed as a fraction of the concentration that would produce the same effect when used singularly (Vuuren et al. 2007, Stanojevic et al. 2010) and may be classified as follows:

FIC of EO $=\frac{\text { MIC of EO in combination with antifungal drug }}{\text { MIC of EO alone }}$

FIC of ketoconazole $=\frac{\text { MIC of antifungal drug in combination with EO }}{\text { MIC of ketoconazole }}$

The FIC index (FICI) was calculated by adding both FICs:

FICI $=$ FIC of essential oil + FIC of ketoconazole and the FICI was interpreted as representing as;

FICI $\leq 0.5=$ synergism effect

FICI $0.5 \leq 1=$ additive effect

FICI 1 to $4=$ indifferent effect

FICI $\geq 4=$ antagonism effect

\section{Results}

In our present study, lavender EOs were analyzed by GC/FID and GC/MS methods and confirmed at the quality of Pharmacopoeia grade. The EOs are characterized by high amounts of linalyl acetate (30.5$42 \%$ ) and linalool (35.9-46\%) (Figures 1 and 2). The major constituents of EOs and their relative percentages are listed in Table 1. The chemical composition of lavender EOs have previously been revealed by different studies with which the EOs were reported to be generally characterized by high levels of linalool, linalyl acetate, lavandulyl acetate, terpinen-4-ol and lavandulol (Cassella et al. 2002, Cavanagh \& Wilkinson 2002, Shellie et al. 2002, Dauria et al. 2005, Lodhia et al. 2009, Sokovic et al. 2010, Danh et al. 2013, Jianu et al. 2013, De Rapper et al. 2013, Yap et al. 2014, De Rapper et al. 2016, Kirımer et al. 2017). The amount of 1,8-cineole and camphor, on the other hand, often varies between very low to moderate (Cavanagh \& Wilkinson 2002, Shellie et al. 2002).

Table 1. Major constituents of lavender EOs.

\begin{tabular}{cccc}
\hline \hline *KI & Compounds & L1 (\%) & L2 (\%) \\
\hline \hline 0939 & $\alpha$-Pinene & - & 3.2 \\
1029 & Limonene & - & trace \\
1031 & 1,8-cineole & 4.8 & 0.7 \\
1097 & Linalool & $\mathbf{4 4 . 0}$ & $\mathbf{3 5 . 8}$ \\
1146 & Camphor & 4.8 & 0.5 \\
1169 & Borneol & 1.6 & 2.9 \\
1177 & Terpinen-4-ol & - & 1.7 \\
1189 & $\alpha$-Terpineol & 1.4 & 1.4 \\
1257 & Linalyl acetate & $\mathbf{3 0 . 5}$ & $\mathbf{3 6 . 0}$ \\
1381 & Lavandulyl acetate & 1.04 & 1.0 \\
\hline TOTAL & & 88.14 & 83.2 \\
\hline \hline
\end{tabular}

*KI: Kovats indices calculated according Adams (2001)

L1 and L2 correspond to two purchased lavender Eos

(-) Not detected
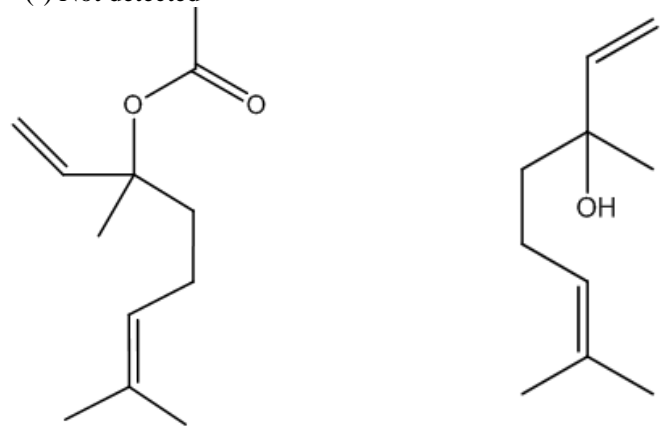

Fig. 1. Linalyl acetate

Fig. 2. Linalool

Resistance of yeast isolates to antifungal drugs, such as fluconazole and ketonazole were reported to increase in serious fungal infections making patient management a complicate case (Sanglard \& Odds 2002, Jamil et al. 2017). Candida species are considered as one of the most important causes of human infections. They may become pathogenic and cause candidiasis under some conditions, such as prolonged antifungal therapy and reduced immunity. Candidiasis range from mild infection such as 
onychomycosis or perlish to potentially fatal systemic candidiasis (Akortha et al. 2009).

Azoles are by far the most commonly used antifungals in clinical treatment with lower cytotoxicity and perfect efficacies. However, their prolonged use has led to the development of drug resistance in Candida species (Hasanbeigi et al. 2005, Magill et al. 2006, Zomorodian et al. 2011).

Many essential oils have been proven to possess antifungal properties and thus they can be potentially used as antifungal agents. As proven in vitro, EOs show effective antifungal activities even against resistant clinical isolates of Candida species. The use of combinations of EOs and their isolated components are thus new approaches to increase their efficacy in fungal treatment, for taking advantage of their synergistic and additive effects (Cleff et al. 2010, Pozzatti et al. 2010, Stringaro et al. 2014).

From this point of view, EOs of lavender tested for their anticandidal activities against Candida strains (Table 2) were found to have a MIC range of $160-640 \mu \mathrm{g} / \mathrm{mL}$ compared to ketoconazole MIC range of 1-4 $\mu \mathrm{g} / \mathrm{mL}$. In particular, the inhibitory effect of L2 EO represented with a MIC value of $160 \mu \mathrm{g} / \mathrm{mL}$ was more pronounced than that of L1 EO when tested with standard and clinical $C$. krusei strains (Table2).

Table 2. MIC values $(\mu \mathrm{g} / \mathrm{mL})$ of EOs and ketoconazole against Candida isolates.

\begin{tabular}{lccc}
\hline \hline Tested Candida isolates & $\begin{array}{c}\text { MIC } \\
\text { values } \\
\text { of L1 } \\
\text { EOs }\end{array}$ & $\begin{array}{c}\text { MIC } \\
\text { values of } \\
\text { L2 EOs }\end{array}$ & $\begin{array}{c}\text { MIC values } \\
\text { of } \\
\text { Ketoconazole }\end{array}$ \\
\hline \hline C. albicans ATCC 10231 & 320 & 320 & 2.0 \\
C. krusei NRRLY-7179 & 320 & 160 & 2.0 \\
\hline C. glabrata ATCC 66032 & 320 & 640 & 2.0 \\
\hline C. albicans clinical isolate & 320 & 320 & 2.0 \\
\hline C. krusei clinical isolate & 320 & 160 & 2.0 \\
\hline C. glabrata clinical isolate & 320 & 320 & 2.0 \\
\hline \hline
\end{tabular}

The checkerboard results of EOs and ketoconazole combinations were listed in Tables 3 and 4 . The L1 + ketoconazole combination against both clinical and standard C. albicans ATCC 10231, C. krusei NRRL Y7179 and $C$. glabrata ATCC 66032 showed additive effects $(\mathrm{FICI}=0.53$ to 056$)$ (Table 3$)$. The $\mathrm{L} 2+$ ketoconazole combination against $C$. albicans $(\mathrm{FICI}=1.0)$ and $C$. glabrata $(\mathrm{FICI}=0.56)$ clinical isolates also resulted in an additive activity pattern (Table 4 ).

In combination therapy, interactions between EOs and antifungals can display four possible types of effects as synergistic, additive, indifferent and antagonistic. Synergism is observed when the effect of the combined substances is greater than the sum of their individual effects. An additive effect is observed when the combined effect is equal to the sum of the individual effects. Indifference is observed when there is no interaction. Antagonism is observed when the effect of one or both compounds is less when they are applied together than when applied individually (Bassole et al. 2012, Yap et al. 2014).

The different interactions observed in antifungal activity between EOs of L1 and L2 can be explained by the chemical compositions EOS and the ratio of their components. Since EOs contain many chemical mixtures, differences can be observed in their antimicrobial effects and the type of effect mechanisms. Most of the antimicrobial activity effect for EOs was attributed to their chemical compositions derived from hydrocarbons, oxygenated terpenoids, particularly phenolic terpenes, phenylpropanoids and alcohols (Burt, 2004).

Lavender EOs have been previously demonstrated to be active against a broad spectrum ranging from Gram positive and Gram negative bacteria to Candida strains (Dauria et al. 2005, Lodhia et al 2009, Sokovic et al. 2010, Danh et al. 2013, Jianu et al. 2013), and thus they were suggested to be useful in treating bacterial and fungal infections including those related with drug resistant strains. Along with their antimicrobial activity, lavender EOs were used in the treatment and relieve of symptoms of skin conditions such as psoriasis, dermatitis and eczema. It has also been suggested that topical application of lavender EOs may inhibit parts of the allergic pathway (Cavanagh \& Wilkinson 2002).

Synergistic antifungal activity of combination of lavender EOs and tea tree oil (Melaleuca alternifolia) against dermatophyte infections were reported (Cassella et al. 2002). De Rapper et al. (2013) investigated the combination of $L$. angustifolia EO with fourty five different aroma therapeutic essential oils against $C$. albicans ATCC 10231, P. aeruginosa ATCC 27858 and $S$. aureus ATCC 6538 . The most favourable interactions were displayed with L. angustifolia and Cinnamomum zeylanicum or with Citrus sinensis EOs against $C$. albicans and $S$. aureus.

L. angustifolia EO was also combined with the commercial antimicrobial drugs nystatin, chloramphenicol, ciprofloxacin and fusidic acid against $S$. aureus ATCC 6538, P. aeruginosa ATCC 27858 and $C$. albicans ATCC 10231. The best interaction was shown between $L$. angustifolia EO with chloramphenicol and tested against the pathogen $P$. aeruginosa $($ FICI=0.29).

The mode of action of lavender EO on antimicrobial activity against multi-drug resistant Escherichia coli J53 R1 when used singly and in combination with piperacillin was demonstrated (Yap et al. 2014). The time-kill analysis showed synergistic interaction between lavender EO and piperacillin at $4 \mathrm{~h}$. The results of this study indicate that lavender EO is able to disrupt membrane structures of $E$. coli and has the potential to inhibit bacterial quorum sensing. 
In conclusion, we reported here for the first time the anticandidal effects of $L$. angustifolia EOs with ketoconazole combination against the standard and clinical strains of the human pathogens $C$. albicans, $C$. glabrata and $C$. krusei in a comparative manner. As revealed by the results, the absence of antagonism may be promising for combination of lavender EOs and ketoconazole in anticandidal use. The effective dose of ketoconazole use in combination may be reduced, rapid drug resistance may be prevented or combination use may provide a solution to drug-drug resistance problems and can be considered a promising alternative pharmaceutical agent for topical application in surface infections. Therefore, lavender EOs should be combined with different antibiotic/antifungal drugs and tested against different pathogens.

Table 3. Fractional inhibitory concentration index (FICI) for L1 EO.

\begin{tabular}{lcccccc}
\hline \hline \multicolumn{1}{c}{ Candida isolates } & $\begin{array}{c}\text { L1 MIC } \\
(\mathrm{alone})(\mu \mathrm{g} / \mathrm{ml})\end{array}$ & $\begin{array}{c}\text { Ketoconazole MIC } \\
(\mathrm{alone})(\mu \mathrm{g} / \mathrm{ml})\end{array}$ & $\begin{array}{c}\text { L1 MIC } \\
(\text { combination })(\mu \mathrm{g} / \mathrm{ml})\end{array}$ & $\begin{array}{c}\text { Ketoconazole MIC } \\
(\mathrm{combination})(\mu \mathrm{g} / \mathrm{ml})\end{array}$ & $\begin{array}{c}\text { FICI } \\
\begin{array}{c}\text { The resulting } \\
\text { interaction type }\end{array}\end{array}$ \\
\hline \hline C. albicans ATCC 0231 & 320 & 2.0 & 160 & 0.06 & 0.53 & Additive \\
C. krusei NRRL Y-7179 & 320 & 2.0 & 10 & 1.0 & 0.53 & Additive \\
C. glabrata ATCC 6032 & 320 & 2.0 & 20 & 1.0 & 0.56 & Additive \\
C. albicans clinical isolate & 320 & 2.0 & 160 & 0.06 & 0.53 & Additive \\
C. krusei clinical isolate & 320 & 2.0 & 160 & 0.06 & 0.53 & Additive \\
C. glabrata clinical isolate & 320 & 2.0 & 10 & 1.0 & 0.53 & Additive \\
\hline \hline
\end{tabular}

Table 4. Fractional inhibitory concentration index (FICI) for L2 EO.

\begin{tabular}{lcccccc}
\hline \hline \multicolumn{1}{c}{ Candida isolates } & $\begin{array}{c}\text { L2 MIC } \\
(\mathrm{alone})(\mu \mathrm{g} / \mathrm{mL})\end{array}$ & $\begin{array}{c}\text { Ketoconazole MIC } \\
(\mathrm{alone})(\mu \mathrm{g} / \mathrm{mL})\end{array}$ & $\begin{array}{c}\text { L2 MIC } \\
(\text { combination })(\mu \mathrm{g} / \mathrm{mL})\end{array}$ & $\begin{array}{c}\text { Ketoconazole MIC } \\
(\text { combination })(\mu \mathrm{g} / \mathrm{mL})\end{array}$ & $\begin{array}{c}\text { FICI } \\
\begin{array}{c}\text { The resulting } \\
\text { interaction type }\end{array}\end{array}$ \\
\hline \hline C. albicans ATCC $\mathbf{1 0 2 3 1}$ & 320 & 4.0 & 320 & 2.0 & 1.5 & Indifferent \\
C. krusei NRRL Y-7179 & 160 & 1.0 & 10 & 2.0 & 2.06 & Indifferent \\
C. glabrata ATCC 66032 & 640 & 4.0 & 640 & 4.0 & 2.0 & Indifferent \\
C. albicans clinical isolate & 320 & 4.0 & 160 & 2.0 & 1.0 & Additive \\
C. krusei clinical isolate & 160 & 1.0 & 80 & 2.0 & 2.05 & Indifferent \\
C. glabrata clinical isolate & 320 & 4.0 & 20 & 2.0 & 0.56 & Additive \\
\hline \hline
\end{tabular}

\section{Acknowledgement}

The authors would like to thank Anadolu University Scientific Research Project: 1301S005 for their financial

\section{References}

1. Amber, K., Aijaz, A., Immaculata, X., Luqman, K.A. \& Nikhat, M. 2010. Anticandidal effect of Ocimum sanctum essential oil and its synergy with fluconazole and ketoconazole. Phytomedicine, 17(12): 921-925.

2. Akortha, E.E., Nwaugo, V.O., \& Chikwe, N.O. 2009. Antifungal resistance among Candida species from patients with genitourinary tract infection isolated in Benin City, Edo state, Nigeria. African Journal of Microbiology Research, 3(11): 694-699.

3. Bassole I.H.N. \& Juliani, H.R. 2012. Essential oils in combination and their antimicrobial properties. Molecules, 17(4): 3989-4006.

4. Burt, S. 2004. Essential oils: their antibacterial properties and potential applications in foods-a review. International Journal of Food Microbiology, 94(3), 223-253. support. Part of this work was presented in International Symposium on Drug Research \& Development held in Antalya, Turkey on 28-30 November, 2013.

5. Casalinuovo, I.A., Di Francesco, P. \& Garaci, E. 2004. Fluconazole resistance in Candida albicans: a review of mechanisms. European Review for Medical and Pharmacological Sciences, 8: 69-78.

6. Cassella, S., Cassella, J.P. \& Smith, I. 2002. Synergistic antifungal activity of tea tree (Melaleuca alternifolia) and lavender (Lavandula angustifolia) essential oils against dermatophyte infection. International Journal of Aromatherapy, 12(1): 2-15.

7. Cavanagh, H.M.A. \& Wilkinson, J.M. 2002. Biological activities of lavender essential oil. Phytotherapy Research, 16(4): 301-308.

8. Chen, Y., Zeng, H., Tian, J., Ban, X., Ma, B. \& Wang, Y. 2013. Antifungal mechanism of essential oil from Anethum graveolens seeds against Candida albicans. Journal of medical microbiology, 62(8): 1175-1183. 
9. Clinical and Laboratory Standards Institute (CLSI). 2002. Reference Method for broth dilution antifungal susceptibility testing of yeast approved standard, M27-A2. 940 West Valley Road, Wayne, Pennsylvania, USA: Clinical and Laboratory Standards Institute.

10. Cleff, M.B., Meinerz, A.R., Xavier, M., Schuch, L.F., Meireles, M.C.A., Rodrigues, M.R.A. \& Mello, J.R.B.D. 2010. In vitro activity of Origanum vulgare essential oil against Candida species. Brazilian Journal of Microbiology, 41(1): 116-123.

11. Cottarel, G. \& Wierzbowski, J. 2007. Combination drugs, an emerging option for antibacterial therapy. Trends in Biotechnology, 25(12): 547-555.

12. Cox, S.D., Mann, C.M., Markham, J.L., Bell, H.C., Gustafson, J.E., Warmington, J.R. \& Wyllie, S.G. 2000. The mode of antimicrobial action of the essential oil of Melaleuca alternifolia (tea tree oil). Journal of Applied Microbiology, 88(1): 170-175.

13. Danh, L.T., Triet, N.D.A., Zhao, J., Mammucari, R. \& Foster, N. 2013. Comparison of chemical composition, antioxidant and antimicrobial activity of lavender (Lavandula angustifolia L.) essential oils extracted by supercritical $\mathrm{CO}_{2}$, hexane and hydrodistillation. Food and Bioprocess Technology, 6(12): 3481-3489.

14. Dauria, F.D., Tecca, M., Strippoli, V., Salvatore, G., Battinelli, L. \& Mazzanti, G. 2005. Antifungal activity of Lavandula angustifolia essential oil against Candida albicans yeast and mycelial form. Medical Mycology, 43(5): 391-396.

15. De Rapper, S., Kamatou, G., Viljoen, A. \& van Vuuren, S. 2013. The in vitro antimicrobial activity of Lavandula angustifolia essential oil in combination with other aromatherapeutic oils. Evidence-Based Complementary and Alternative Medicine, 2013: 852049.

16. De Rapper, S., Viljoen, A. \& van Vuuren, S. 2016. The in vitro antimicrobial effects of Lavandula angustifolia essential oil in combination with conventional antimicrobial agents. Evidence-Based Complementary and Alternative Medicine, 2016: 2752739.

17. ESO 2000, 1998. The Complete database of essential oils. The Netherlands: Boelens Aroma Chemical Information Service.

18. Fismer, K. L., \& Pilkington, K. 2012. Lavender and sleep: A systematic review of the evidence. European Journal of Integrative Medicine, 4(4), 436-447.

19. Göger, G., Demirci, B., Ilgın, S. \& Demirci, F. 2018. Antimicrobial and toxicity profiles evaluation of the chamomile (Matricaria recutita $\quad$ L.) essential oil combination with standard antimicrobial agents. Industrial Crops and Products, 120: 279-285.

20. Hasanbeigi, A., Shahmir, P. \& Amraie, M. 2015. Study of antifungal resistance of Candida types against some of common antifungal drugs. International Journal of Pharmaceutical Sciences Research, 6(2): 241.

21. Hosseinzadeh, S., Jafarikukhdan, A., Hosseini, A., \& Armand, R. 2015. The application of medicinal plants in traditional and modern medicine: a review of Thymus vulgaris. International Journal of Clinical Medicine, 6(09), 635.
22. Joulain D. \& Koenig, W.A. 1998. The Atlas of spectra data of sesquiterpene hydrocarbons. Hamburg: EB-Verlag.

23. Jamil, B., Bokhari, M.T.M., Saeed, A., Bokhari, M.Z.M., Hussain, Z., Khalid, T. \& Abbasi, S. A. 2017. Candidiasis: Prevalence and resistance profiling in a tertiary care hospital of Pakistan. JPMA. The Journal of the Pakistan Medical Association, 67(5): 688.

24. Jianu, C., Pop, G., Gruia, A.T. \& Horhat, F.G. 2013. Chemical composition and antimicrobial activity of essential oils of lavender (Lavandula angustifolia) and lavandin (Lavandula $x$ intermedia) grown in Western Romania. International Journal of Agriculture and Biology, 15(4): 772-776.

25. Kırımer, N., Mokhtarzadeh, S., Demirci, B., Goger, F., Khawar, K.M., \& Demirci, F. 2017. Phytochemical profiling of volatile components of Lavandula angustifolia Miller propagated under in vitro conditions. Industrial Crops and Products, 96: 120-125.

26. Koenig, W.A., Joulain, D. \& Hochmuth, D.H. 2001. Terpenoids and related constituents of essential oils. Library of MassFinder 2.1. Hamburg.

27. Khan, A., Ahmad, A., Akhtar, F., Yousuf, S., Xess, I., Khan, L.A., \& Manzoor, N. 2010. Ocimum sanctum essential oil and its active principles exert their antifungal activity by disrupting ergosterol biosynthesis and membrane integrity. Research in Microbiology, 161(10): 816-823.

28. Lodhia, M.H., Bhatt, K.R. \& Thaker, V.S. 2009. Antibacterial activity of essential oils from palmarosa, evening primrose, lavender and tuberose. Indian Journal of Pharmaceutical Sciences, 71(2): 134.

29. Magill, S.S., Shields C., Sears, C.L., Choti, M. \& Merz, W.G. 2006. Triazole cross-resistance among Candida spp.: Case report, occurrence among bloodstream isolates, and implications for antifungal therapy. Journal of Clinical Microbiology, 44: 529-535.

30. Metzger, S. \& Hofmann, H. 1997. Fluconazole-resistant Candida species from HIV infected patients with recurrent Candida stomatitis: cross resistance to itraconazole and ketoconazole. Mycoses, 40: 56-63.

31. McLafferty, F.W. \& Stauffer, D.B. 1989. The Wiley/NBS Registry of Mass Spectral Data. J. Wiley and Sons, New York.

32. Pinto, E., Pina-Vaz, C., Salgueiro, L., Gonçalves, M. J., Costa-de-Oliveira, S., Cavaleiro, C. \& Martinez-deOliveira, J. 2006. Antifungal activity of the essential oil of Thymus pulegioides on Candida, Aspergillus and dermatophyte species. Journal of Medical Microbiology, 55(10): 1367-1373.

33. Pinto, E., Vale-Silva, L., Cavaleiro, C. \& Salgueiro, L. 2009. Antifungal activity of the clove essential oil from Syzygium aromaticum on Candida, Aspergillus and dermatophyte species. Journal of Medical Microbiology, 58(11): 1454-1462.

34. Pfaller, M.A., Diekema, D.J., Gibbs, D.L., Newell, V.A., Nagy, E. \& Dobiasova, S. 2008. Global Antifungal Surveillance Group. 2008. Candida krusei, a multidrugresistant opportunistic fungal pathogen: geographic and temporal trends from the ARTEMIS DISK Antifungal 
Surveillance Program, 2001 to 2005. Journal of Clinical Microbiology, 46(2): 515-521.

35. Pozzatti, P., Loreto, E.S., Lopes, P.G.M., Athayde, M.L., Santurio, J.M. \& Alves, S.H. 2010. Comparison of the susceptibilities of clinical isolates of Candida albicans and Candida dubliniensis to essential oils. Mycoses, 53(1): 1215.

36. Samber, N., Khan, A., Varma, A., \& Manzoor, N. 2015. Synergistic anti-candidal activity and mode of action of Mentha piperita essential oil and its major components. Pharmaceutical Biology, 53(10): 1496-1504.

37. Sanglard, D. \& Odds, F. C. 2002. Resistance of Candida species to antifungal agents: molecular mechanisms and clinical consequences. The Lancet Infectious Diseases, 2(2): 73-85.

38. Sardi, J.C.O., Scorzoni, L., Bernardi, T., Fusco-Almeida, A.M. \& Mendes Giannini, M.J.S. 2013. Candida species: current epidemiology, pathogenicity, biofilm formation, natural antifungal products and new therapeutic options. Journal of Medical Microbiology, 62: 10-24.

39. Shin, S. \& Kang, C.A. 2003. Antifungal activity of the essential oil of Agastache rugosa Kuntze and its synergism with ketoconazole. Letters in Applied Microbiology, 36: 111-115.

40. Shin, S. 2003. Anti-Aspergillus activities of plant essential oils and their combination effects with ketoconazole or amphotericin B. Archieves of Pharmacal Research, 26: 389-393.

41. Shellie, R., Mondello, L., Marriott, P. \& Dugo, G. 2002. Characterisation of lavender essential oils by using gas chromatography-mass spectrometry with correlation of linear retention indices and comparison with comprehensive two-dimensional gas chromatography. Journal of Chromatography A, 970(1-2): 225-234.
42. Sokovic, M., Glamoclija, J., Marin, P.D., Brkic, D. \& Van Griensven, L.J. 2010. Antibacterial effects of the essential oils of commonly consumed medicinal herbs using an in vitro model. Molecules, 15(11): 7532-7546.

43. Stringaro, A., Vavala, E., Colone, M., Pepi, F., Mignogna, G., Garzoli, S. \& Angiolella, L. 2014. Effects of Mentha suaveolens essential oil alone or in combination with other drugs in Candida albicans. Evidence-Based Complementary and Alternative Medicine, Volume 2014, Article ID 125904, 9 pp.

44. Stanojevic, D., Comic, L., Stefanovic, O. \& SolujicSukdolak, S. 2010. In vitro synergistic antibacterial activity of Salvia officinalis L. and some preservatives. Archives of Biological Sciences Belgrade, 62(1): 175-83.

45. Vuuren, S.V. \& Viljoen, A.M. 2007. Antimicrobial activity of limonene enantiomers and 1,8-cineole alone and in combination. Flavour and Fragrance Journal, 22(6): 540544.

46. Van Vuuren, S.F., Suliman, S. \& Viljoen, A.M. 2009. The antimicrobial activity of four commercial essential oils in combination with conventional antimicrobials. Letters in Applied Microbiology, 48(4): 440-446.

47. Yap, P.S.X., Krishnan, T., Yiap, B.C., Hu, C.P., Chan, K.G. \& Lim, S.H.E. 2014. Membrane disruption and antiquorum sensing effects of synergistic interaction between Lavandula angustifolia (lavender oil) in combination with antibiotic against plasmid-conferred multi-drug-resistant Escherichia coli. Journal of Applied Microbiology, 116(5): 1119-1128.

48. Zomorodian, K., Rahimi, M.J., Pakshir, K., Motamedi, M., Ghiasi, M.R. \& Rezashah, H. 2011. Determination of antifungal susceptibility patterns among the clinical isolates of Candida species. Journal of Global Infectious Diseases, 3(4): 357. 